https://dx.doi.org/10.36380/scil.2019.wvj29

\title{
Computed Tomography Scan and Polyester resin 40 Plastination Technique: Teaching Aids to Illustrate Anatomical Structure of Donkey Brain
}

\author{
Sherif Khayri Abdelmoati Mohamed ${ }^{1,2 *}$, Eman Ismail El-behery ${ }^{1}$ and Eman Abd El-Rahman Ahmed Mahdy ${ }^{1}$ \\ ${ }^{1}$ Department of Anatomy and Embryology, Faculty of Veterinary Medicine, Zagazig University, Zagazig 44511, Egypt \\ ${ }^{2}$ Faculty of Veterinary Medicine, Basic Veterinary Sciences, Hokkaido University, Sapporo 060-0818, Japan \\ * Corresponding author's Email: sherifanatomy81 @ gmail.com; ORCID: 0000-0003-4226-2423
}

\begin{abstract}
The present study investigated the collaboration between the plastinated sagittal sections and computed tomography (CT) images of the donkey brain. Four adult healthy donkeys of both sexes from native breeds were analyzed. The animals were sedated with a combination of xylazine and ketamine. The donkeys were positioned in sternal recumbency during CT brain examination and contiguous sagittal $3 \mathrm{~mm}$ thick slices of the head were obtained. Polyester resin 40 (P40) technique for the brains were done through five main steps including fixation, slicing, dehydration, forced impregnation and light-curing of brain glass chambers by UVA light source. Furthermore, a survey was conducted using questionnaires involving second-year veterinary medical students of anatomy department, Zagazig University to compare the educational capacity of CT brain images and P40 plastination of brain slices. $52 \%$ of students voted that using of brain sheeted slices are much better, $38 \%$ prefer to learn both parallel to each other. The obtained results revealed that both the plastinated brain sections and the CT images portrayed a combination of many complex neuroanatomical structures that provide an excellent aid for researchers in educational and diagnostic purposes. In addition, the plastinated brain serves as a good tool for the interpretation of CT images.
\end{abstract}

Key words: Brain, CT, Donkey, Plastination, Polyester resin 40

\section{INTRODUCTION}

Plastination is one of the standard methods for preservation of biological tissues and it is used in many fields such as anatomy, art, biology, clinics, and medicine (Henry and Latorre 2007). Plastinated slices require low storage space and are stable, inodorous and non-toxic, thus they are applied as a good teaching tool in veterinary anatomy. The plastinated slices are well preserved and excellent for demonstration compared to the harmful formalinized specimens. However, they could not completely replace the traditional method as students learning will be best by hands-on dissection. Shrinkage, discoloration, high-price and need to a well-trained person are the major problems associated with plastination technique (Reda and Roger, 2018 and Renukaradhya et al., 2018).

The plastinated specimens are useful in self-learning and research, thus facilitate the teaching of neuroanatomy, the lifelike visualization of specimens of the central and peripheral nervous system. P40 plastination technology is a specific module for the tissue preservation and production of polyester plastinated brain slices which have been used in teaching and research (Latorre et al., 2002 and Sivrev et al., 2013). The Biodur ${ }^{\mathrm{TM}}$ P35 resin was used in1980s for the preparation of brain sections with a thickness of 4-8mm (Von Hagens et al., 1987). The P40 resin was introduced in the mid-1990s as a less complicated process to produce thinner brain slices giving better white and gray matter differentiation (Von Hagens, 1994).

Computed Tomography (CT) is an important tool for the investigation of intracranial disease in humans. Recently, this technique has become more available to veterinarians and has used for the diagnosis of brain disorders in horses, ruminants, and carnivores. The neurodegenerative diseases, tumors, cysts, hemorrhage, brain infarction, congenital anomalies, and hydrocephalus could be detected and diagnosed by using CT scans (Lieve et al., 2005).

Radiographic assessment of the equine skull is difficult due to its complex anatomy. The location and extent of lesions in the head region are often difficult to define by clinical and radiographic examination. CT scanning is particularly useful for studying the complex anatomical structures due to the ability to obtain transverse and midsagittal images and manipulate its contrast and latitude (Karen et al., 2000).

The use of CT scan in the anatomical investigation and clinical examination of Equidae is still very limited due to unsuitable design of the $\mathrm{CT}$ machine for big-sized horses and its high expense. The $\mathrm{CT}$ scanners used in veterinary 
medicine are designed for human patients. Hence, these machines are only suitable for small-sized animals such as donkeys (Cabreraa et al., 2015). P40 and CT carrels are available for the learning of neuroanatomy and describing the most complex parts of the nervous system such as the brain.

A survey of both teaching modules was done on the second-year veterinary students. The purpose of the present study was to reveal the benefits of applying the P40 plastinated brain sections in matching with CT images. To be more combination of P40 and CT techniques can be used for better understanding and imagination to the most complex anatomy parts of the donkey brain which also confers accurate interpretation of CT images. Both these tools can also be used in the clinical training of medical students in the neurosurgery and radiological anatomy.

\section{MATERIALS AND METHODS}

\section{Ethical approval}

Prior approval from Institutional Animal Care and the Research Ethics Committee of the Zagazig (approval no. ZU-IACUC/2/F /92/2018) was obtained.

\section{Animals}

Four adult healthy donkeys (more than two-years-old) of both sexes from native breeds were selected from different farms in Sharkia Governorate, Egypt. Food was withheld for 24 hours prior to sedation. Donkeys were sedated with a combination of xylazine $(1.1 \mathrm{mg} / \mathrm{kg})$ and ketamine $(0.05-0.1 \mathrm{mg} / \mathrm{kg})$ via the intravenous route (Nora and Tex, 2002). First, animals were exposed to CT radiation then the brains were used for the P40 plastination technique.

\section{Computed tomography technique}

The CT scanning was performed at the Emergency Hospital in Zagazig, Sharkia Governorate, Egypt. The donkeys were placed in sternal recumbency, with the head and neck was extended and supported on a sandbag. Contiguous sagittal $3 \mathrm{~mm}$ slices of the brain were obtained using standard CT protocols. CT images were taken without contrast medium by applying a couch index 10.00, RVP 140, MA 108, MAS 225, imaging time 2.2 sec, using CT scanner capable of acquiring up to 32 slices per second with a fast whole-body scan time of 0.5 seconds (third-generation equipment, TOSHIBA 600 HQ, Japan) (Jonathon et al., 2016).

\section{Polyester resin 40 technique}

Polyester resin 40 (P40) technique was performed in P40 room of Zagazig Plastination Laboratory in five steps as described by Henry and Latorre (2007)

\section{Fixation}

After scanning, the donkeys were injected with $10 \%$ formalin solution through the common carotid artery. The skulls were crushed to observe the brains after 4 weeks. To good fixation, the obtained brains were kept in $5 \%$ formalin solution for another 1-2 weeks. A well-fixed firm brain was desirable for slicing on a rotatory meat slicer.

Slicing

The well-fixed brains were kept at $-20{ }^{\circ} \mathrm{c}$ for $36-48 \mathrm{~h}$ for better slicing of the brain using a rotary meat slicer to produce 4-6 mm thick sections for P40 technique of plastination (Figures $1 \mathrm{~A}$ and B).

The prepared brain sections were rinsed in distilled water at $3-5^{\circ} \mathrm{c}$ for $24-48$ hours.

\section{Dehydration (Freeze Substitution)}

The brain slices were placed in a closed bath containing cold pure acetone at $-20{ }^{\circ} \mathrm{C}$ for $2-4$ days to remove the water and lipid content. The ratio of specimen weight to volume of acetone was 1:10 (Figure 1C).

\section{Forced impregnation}

The dehydrated sections were imbedded into the liquid polyester P40 under vacuum and cool conditions. The vacuum drew out the acetone from the tissue and was replaced by the polymer. Equipment needed for this step included explosive proof freezers, vacuum chamber, vacuum pump, vacuum control unit, and wire boxes. This step took 5-7 days and included the following three procedures:

1. Low pressure immersion. After the dehydration process, the brain sliced sections were quickly immersed in a polymer solution ( $20 \mathrm{ml}$ of hardener A9 added to one-liter of polyester resins "P40 ") at $4^{\circ} \mathrm{C}$. First, low pressure (2-3mm $\mathrm{Hg}$ ) of vacuum was used for 30 minutes to remove the excessive air-bubbles in the specimens then samples were kept overnight in the first polymer mixture at $4^{\circ} \mathrm{C}$. Polymer solution must be kept in dark bottles (Figures 1D and 2A).

2. High pressure immersion. The polymer solution was replaced three times at $24 \mathrm{~h}$ intervals under a low vacuum level. After replacing the third polymer mixture, the pressure was increased up to $12 \mathrm{~mm} \mathrm{Hg}$ overnight in the dark vacuum chamber at room temperature. The vacuum chamber should be kept in a dark place (Figures 1D and 2A).

3. Preparation of the plastinated sheets. a) Two glass plates were used to prepare a flat chamber suitable for $4 \mathrm{~mm}$ brain slices. The two plates were separated by a flexible, elastic gasket with $6 \mathrm{~mm}$ thickness and then compressed by 
large fold-back clamps. The slices were carefully placed into the chamber after completion of immersion in the polymer solution (Figure 2B); b) The flat glass chamber was filled with a freshly prepared polymer mixture, then due to air bubbles interfere with the curing of the $\mathrm{P} 40$ resin, $1 \mathrm{~mm}$ wire was used to remove them (Figure 2B).

\section{Light curing}

To start the process of polymerization, a 200 Watt Ultraviolet A (UVA) light source was used for 45 minutes to be exposed on both sides of the glass chamber which act as the catalyst. During UVA light exposure, the flat chamber should be cool as the temperature can damage the slices. After that, the flat chamber was placed in an oven at $40{ }^{\circ} \mathrm{C}$ for six days or under sun rays for two weeks to complete the polymerization process. When hardening of the slices was completed, the flat chamber was dismantled, and a scalpel blade was used to score along the length of the junction of the glass with the resin on one or more sides. The brain plastinated slices were covered with plastic foil after trimming any excessive polymer with a band saw or sandpapers (Figure 2C). Eventually, the obtained brain P40 slices were photographed and correlated with the CT images to identify the normal anatomical structures of the brain. The nomenclatures were taken as a basis for the denomination on the brain (NAV, 2017).

\section{Survey of dichotomous questions}

A questionnaire survey was conducted among second-year undergraduate veterinary medical students at the Faculty of Veterinary Medicine, Zagazig University. The plastinated brain slices along with printed labeled CT images of corresponding levels were distributed among 100 students in practical sessions at anatomy departments. Students were asked to write their opinions regarding the preferable method for brain teaching aid.
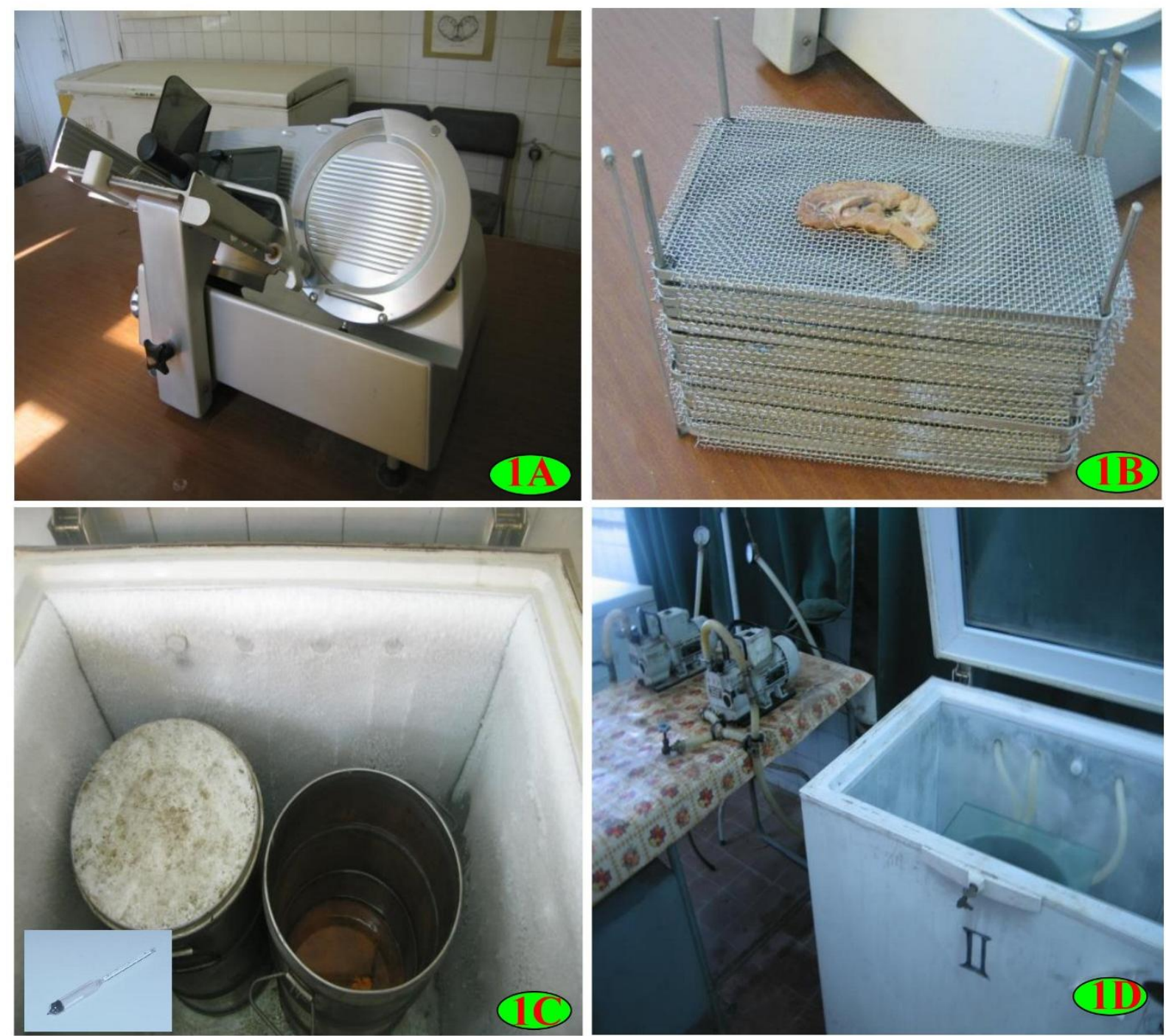

Figure 1. P40 room in Plastination Laboratory, Zagazig University. A: Rotary meat slicer used in sheet brain plastination for cutting the latter fixed brain during P40 technique, blade diameter: $210 \mathrm{~mm}$ : rotate speed: $8000 \mathrm{round} / \mathrm{min}$ (adjustable). Slice thickness adjustment: $4 \mathrm{~mm}$; B: Stainless steel grids as a carrier of brain slices; C: Freezer containing two dehydration acetone panels and an acetonometer using in the step of dehydration of the latter fixed slices and D: Freezer containing P40 filled kettle which connects with vacuum pump and a monitor using in the step of forced impregnation of the latter dehydrated slices. 

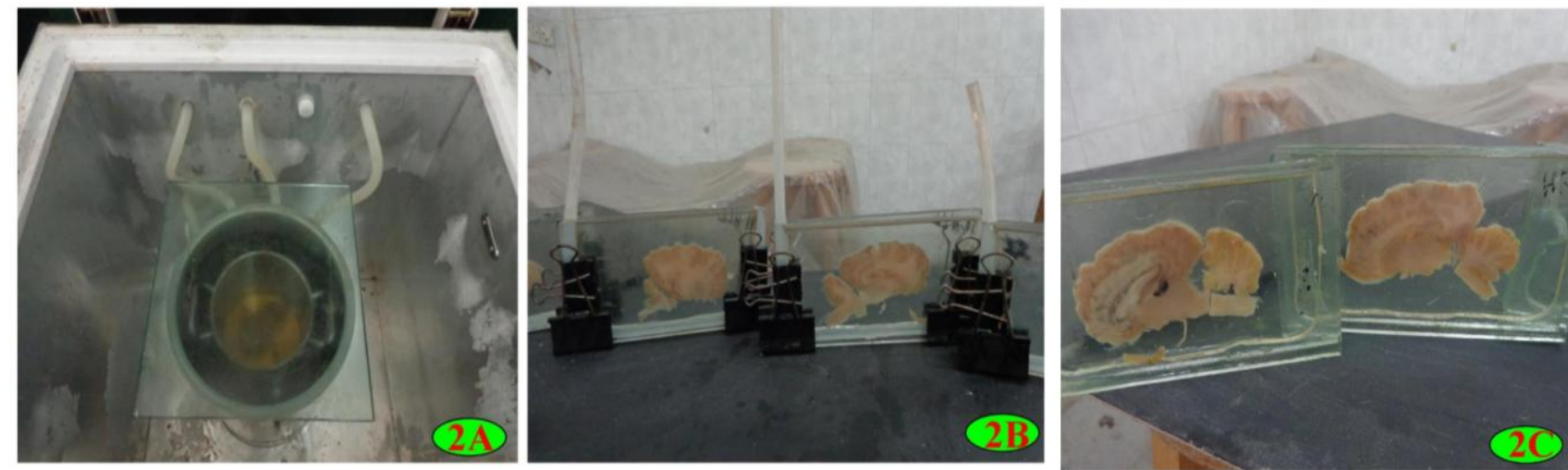

Figure 2. P40 room in Plastination Laboratory, Zagazig University. A: Forced impregnation step of the dehydrated sections under vacuum (glass covering); B: Glass brain chambers of $6 \mathrm{~mm}$ space, silicon gasket and fixation clips filled with the polymer imbedded brain sections and $\mathbf{C}$ : Glass brain chambers after curing and removing the silicon gasket and fixation clips.

\section{RESULTS}

\section{CT brain images}

The present study revealed that some cranial structures could be seen obviously in the plastinated slices while not be seen on its corresponding CT images, and vice versa which may be due to CT artifacts. The widest area of the donkey brain measured from the right to the left cerebral hemispheres was about $5.5-6.5 \mathrm{~cm}$. Fourteen sagittal sections of the formalinized donkey brains were sliced (seven sections for each right and left hemisphere) using the meat rotatory slicer and correlated with the corresponding obtaining CT images. The thickness of each section was about $4 \mathrm{~mm}$. CT scans and the corresponding P40 longitudinal sections were labeled anatomically.

The white and gray matter differentiation was clear in CT scanning while optical quality was better inP40 sections (Figures 3A, 3B, 3C, 3D, 4A and 4B). All four ventricles and the mesencephalic aqueduct were more clearly visible in $\mathrm{CT}$ images due to the presence of radiolucent CSF compared to plastinated sections. In contrast, the choroid plexuses within these ventricles and the central canal were not detected in CT images. Ventriculus lateralis with a width measuring $1.6 \mathrm{~cm}$, was only apparent in $\mathrm{CT}$ images of the first six sagittal sections (Figures 4C, 5A and 5C) but Ventriculus lateralis could be found in both CT and P40 images of the last seven sagittal section of the brain (Figure 6A and $6 \mathrm{~B}$ ). Also, ventriculus tertius was extended around the interthalamic adhesion and aqueductus cerebri was located dorsal to crus cerebri (Figures 5C, 6A and 6B). The width of both structures was about $0.8 \mathrm{~mm}$.

Ventriculus quartus, measuring $0.8 \mathrm{~mm}$ in width, appeared along the ventral aspect of the cerebellum in two images of CT scanning (Figures 5C and 6A), also it was detected in last paramedian P40 slice (Figure 6B). The width of the brain ventricles was approximately $1.6 \mathrm{~mm}$ extended along four CT scans (Figures 4C, 5A, 5C and 6A) that could be easily identified in CT scanning rather than plastinated sections. Cerebrospinal fluid was visualized inside ventriculus lateralis, tertius, quartus, and aqueductus cerebri as black color. On the other hand, not all cranial nerves could be seen in CT images or P40 slices, except nervus olfactorii, nervus opticus, nervus oculomotorius (Figures 4, 5 and 6).

Hemispherium cerebri was detected in all CT and P40 levels that included the whole diameter of donkey brain which was $5.6 \mathrm{~mm}$, while cerebellum was only extended along the thickness of four sections (Figures 4, 5 and 6). Some anatomic features of the cerebrum and cerebellum were not well visualized. In addition, most of the bony boundaries seen on the CT images were also identified and labeled in figure 3A.

\section{P40 brain sections}

Sheet plastinated donkey brain sections (4-6 mm thickness, longitudinal cut) by P40 technique provided a teaching module which gives durable, semi-transparent, flexible and less susceptible to damage and can easily be correlated with CT images. Fourteen semi-transparent P40 brain sections were sliced to clarify more macroscopic details such as some nuclei and nerve bundles which appeared as darker than white matter. These details enhance the teaching method of neuroanatomy to medical students, anatomists, radiologists, and physiotherapists.

Brain P40 sections provided good differentiation between the darker zones of prosencephalon (commissura grisea and basal nuclei) and the lighter one (commissura alba) of hemispherium cerebelli (Figures 3, 4, 5 and 6). Fissura sylvii were only observable in P40 sections (Figure 3B). One of the darker areas which can be easily seen in P40 sections in comparison to CT images was nucleus caudatus that formed the rostral part of the bottom of ventriculus lateralis and accompanied it for four slices. This nucleus consists of two parts; a very large rostral head that related to ventriculus lateralis and corpus callosum and a small caudal tail part situated dorsally to the thalamus (Figures 4, 5 and 6). Another dark nucleus is putamen which is situated lateral to the rostral head part and just lateral to putamen could find capsula 
externa followed by Claustrum (Figure 4B). Capsula interna was found lateral to nucleus caudatus and ventral to thalamus and also separated them. Thalamus was located ventromedial to the two parts of nucleus caudatus (Figures 4,5 and 6). Thalamus was the large nervous band of diencephalon which fused sagittaly with thalamus in the opposite side forming adhesio interthalamica (Figures 4, 5 and 6). Just lateral to thalamus, nucleus geniculatus lateralis was located which is convex or semicircular and surrounded by thalamus (Figure 3D). Ventriculus tertius extended and accompanied corpus pinealis for shorter distance (Figure 6A and 6B). The dorsal structure of mesencephalon is corpora quadrigemina which consists of four large colliculi, two rostral and two posterior colliculi (Figures 4 and 5). The ventral part of mesencephalon is Crus cerebri (Figure 6A and 6B). Ventriculus quartus and Plexus choroideus ventriculi quarti were located dorsal to medulla oblongata and ventral to cerebellum which connected rostrally with aqueductus cerebri and posteriorly with canalis centralis medullae spinalis (Figures 5C, 6A and 6B). Broken sections were one of the defects during the slicing technique of the brain. This may be due to excessive freezing of brain which led to a distortion of the brain tissue by the rapid slicer knife. Immersion of the brain slices in acetone should not exceed 10-14 days, because it may lead to shrinkage if kept for a longer period. Minimal or normal shrinkage was obtained within 7-10 days and reached $8 \%$ in fixed and plastinated specimens (Figure 6C and 6D).
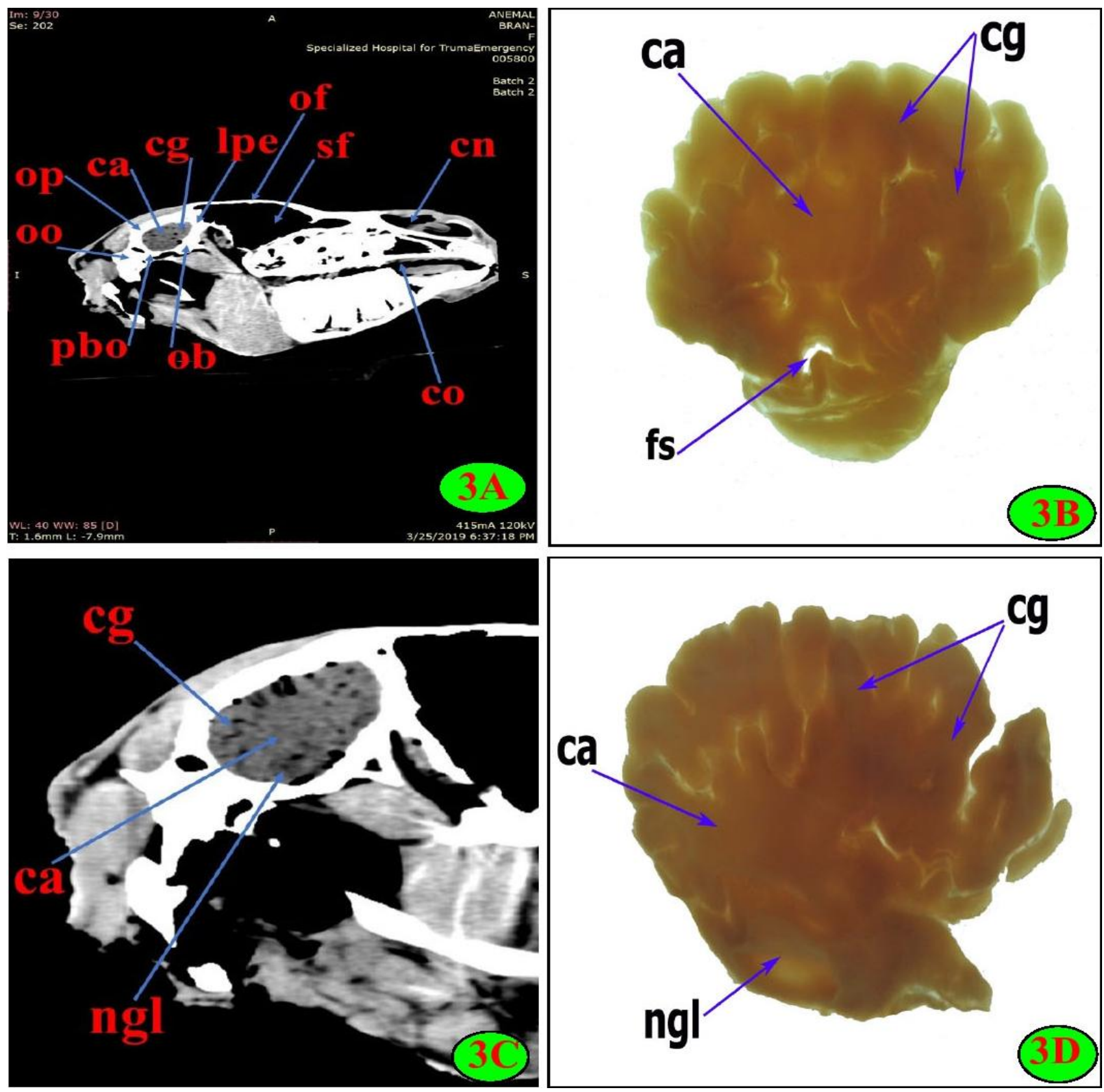

Figure 3. The computed tomographic images of donkey head (cranium region) $(A, C)$ in corresponding to the same levels of plastinated longitudinal brain sections (P40) (Left half of brain) (Medial view) (B,D). Fissura sylvia (fs), Commissura alba (ca), Commissura grisea (cg), Os occipitale (oo), Pars basilaris occipitale (pbo), Os basisphenoidale (ob), Cavum nasi (cn), Cavum oris (co), Os frontale (of), Sinus frontalis (sf), Os parietale (op), Lamina perpendicularis ethmiodale (lpe) and Nucleus geniculatus lateralis (ngl). 

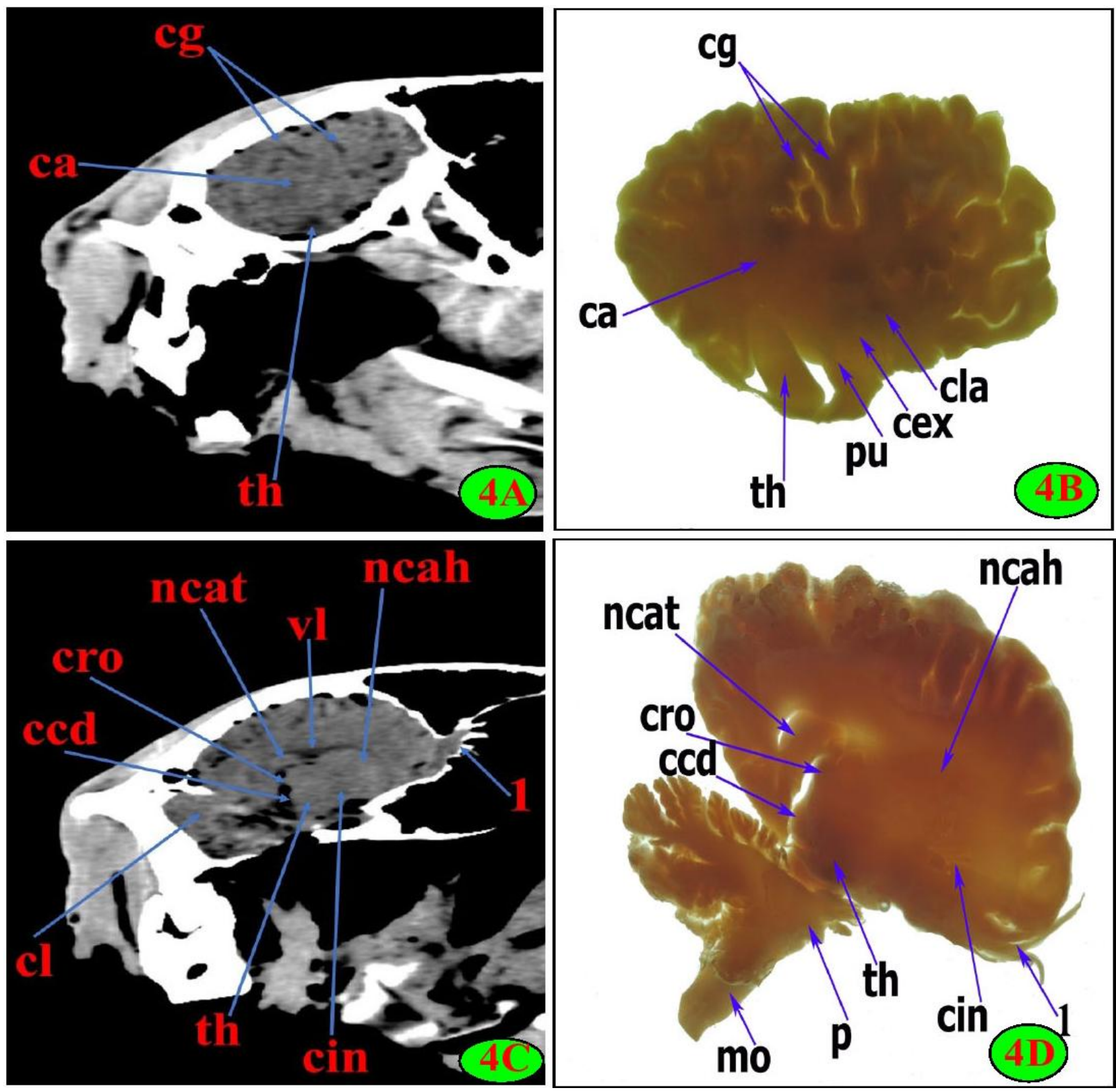

Figure 4. The computed tomographic images of donkey head (cranium region) $(\mathrm{A}, \mathrm{C})$ in corresponding to the same levels of plastinated longitudinal brain sections (P40) (Left half of brain) (Medial view) (B,D). Commissura alba (ca), Commissura grisea (cg), Thalamus (th), Putamen (pu), Capsula externa (cex), Claustrum (cla), Nucleus caudatus (tail) (ncat), Colliculus rostralis (cro), Colliculus caudalis (ccd), Nucleus caudatus (head) (ncah), Capsula interna (cin), Nervi olfactorii (1), Pons (p), Medulla obligate (mo), Cerebellum (cl) and Ventriculus lateralis (vl). 

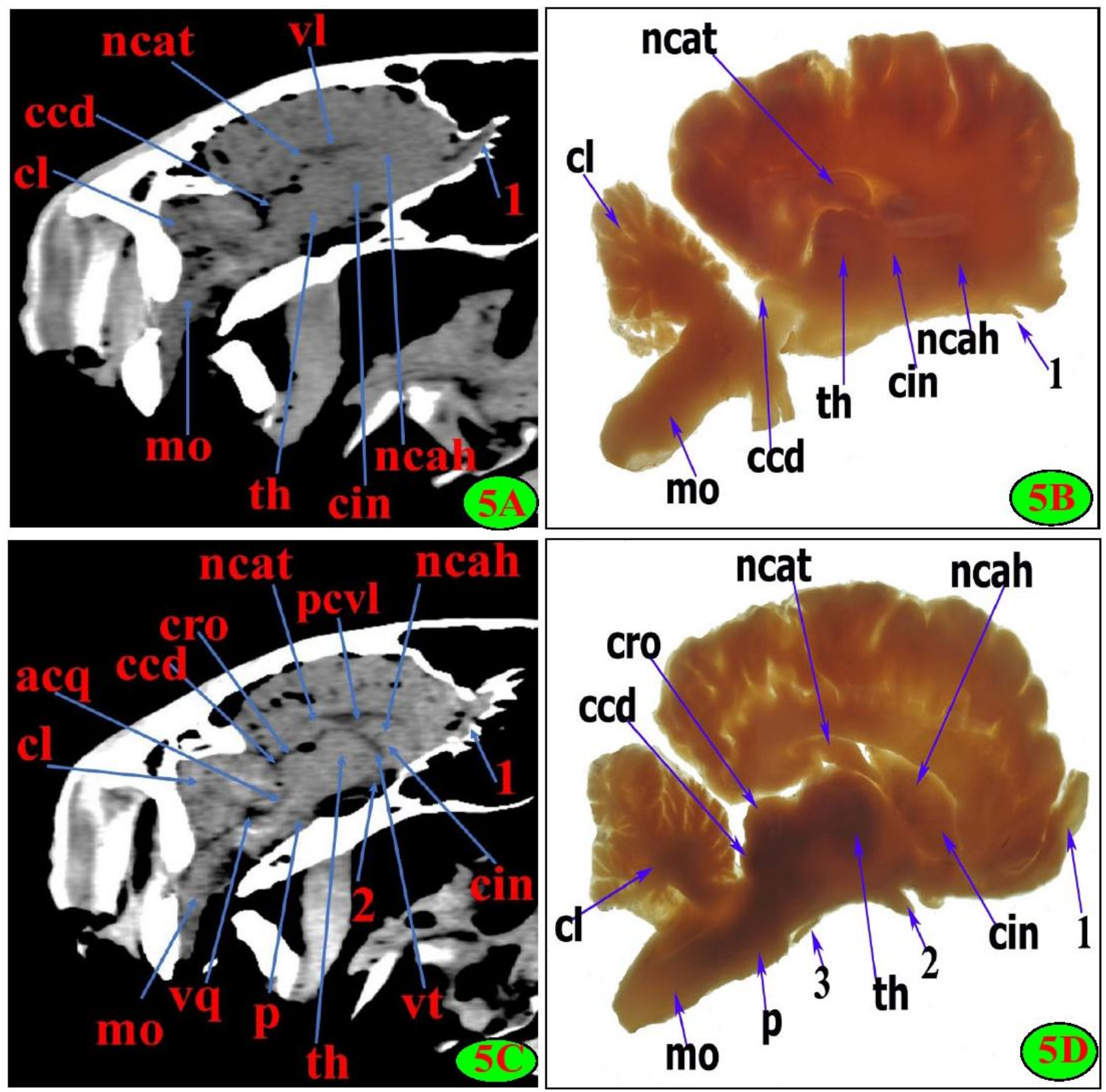

Figure 5. The computed tomographic images of donkey head (cranium region) $(A, C)$ in corresponding to the same levels of plastinated longitudinal brain sections (P40) (Left half of brain) (Medial view) (B,D). Thalamus (th), Nucleus caudatus (tail) (ncat), Colliculus rostralis (cro), Colliculus caudalis (ccd), Nucleus caudatus (head) (ncah), Capsula interna (cin), Nervi olfactorii (1), Pons (p), Medulla obligate (mo), Cerebellum (cl), Ventriculus lateralis (vl), Nervus opticus (2), Nervus oculomotorius (3), Plexus choroidea ventriculus quartus (pcvl), Aqueductus cerebri (aqc) and Ventriculus tertius (vt). 

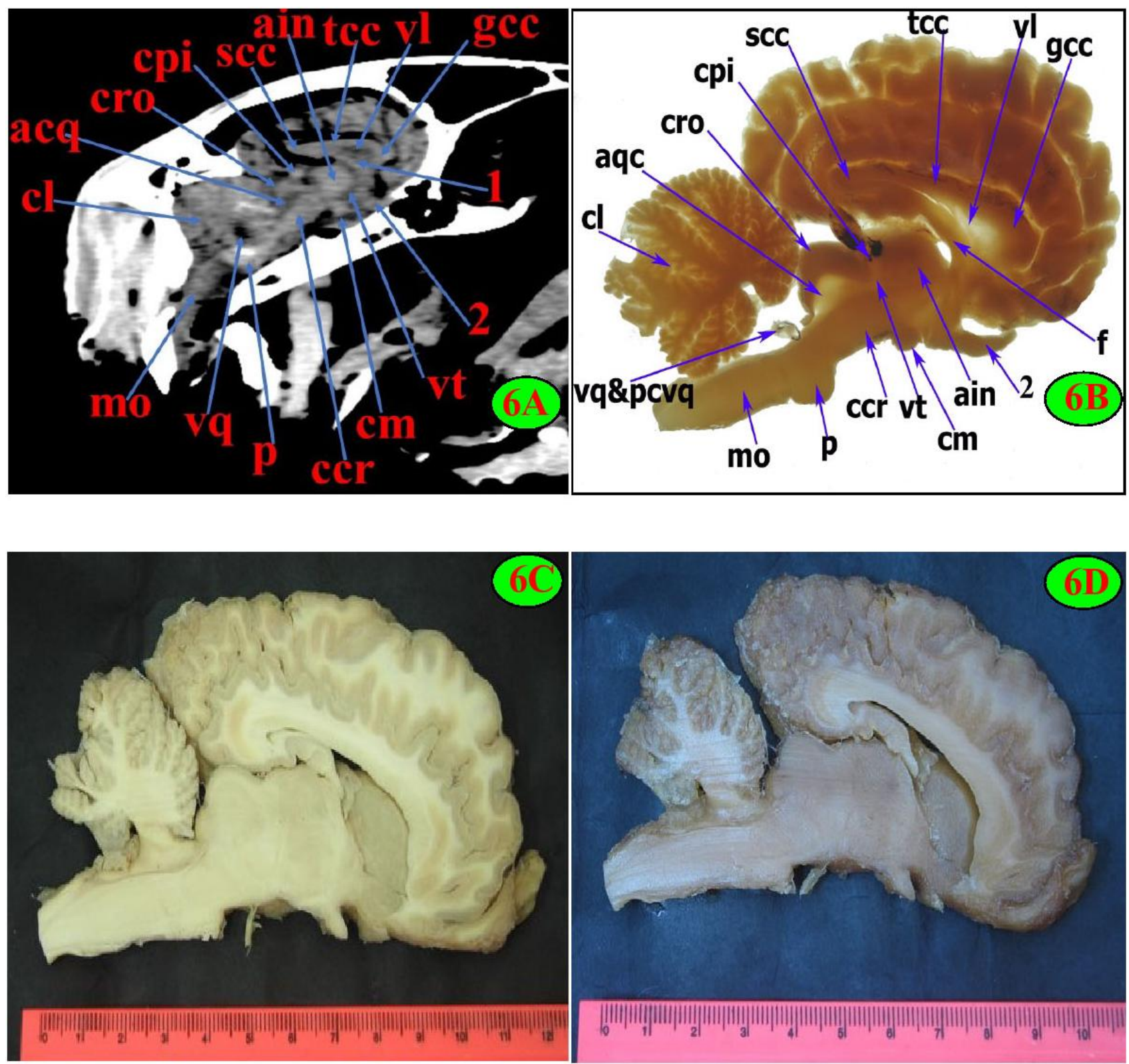

Figure 6. The computed tomographic image of donkey head (cranium region) (A) in corresponding to the same level of plastinated longitudinal brain section (P40) (Left half of brain) (Medial view) (B). Colliculus rostralis (cro), Nervi olfactorii (1), Pons (p), Medulla obligate (mo), Cerebellum (cl), Ventriculus lateralis (vl), Nervus opticus (2), Aqueductus cerebri (aqc), Adhesio interthalamica (ain), Corpus pinealis (cpi), Crus cerebri (ccr), Genu corporis callosi (gcc), , Ventriculus tertius (vt), Truncus corporis callosi (tcc), Splenium corporis callosi (scc), Fornix (f), Corpus mamillare $(\mathrm{cm})$ and Ventriculus quartus and Plexus choroidea ventriculus quartus (vq\&pcvl); Formalinized $4 \mathrm{~mm}$ paramedian section of the left half of the donkey brain before immersion stage; total length: $12.3 \mathrm{~cm}$ (Section 7) (Medial view) (C) and after immersion stage; total length: $10 \mathrm{~cm}(\mathbf{D})$.

\section{Survey}

The survey described the opinion of 100 second-year veterinary medical students from Anatomy and Embryology department about using different self-learning anatomical tools including CT brain images and P40 brain slices. A majority of students $(52 \%)$ expressed that using plastinated slices are better teaching aid as it is sensible, handable and depicts most of the brain anatomical structures. In this survey, 38\% of students preferred to learn through both the techniques to compensate the invisible structures in one technique. Only $5 \%$ of students opined that both the techniques are equal for learning. Five percent mentioned that the CT images create more interest and motivation as well as availability at any time and easy storage makes them a preferable method. All the students strongly agreed that these methods were supporting and very useful in self-studying at home. 
Long exposure to formaldehyde gas is hazardous to health (carcinogenic, mutagenic and toxic effects). Formaldehyde discolors the tissues and emits vapors which are irritant to the eyes and respiratory tract. Repeated and long exposure to formalin can be lead to cancer of the respiratory system, asthma, and bronchitis (Sivrev et al., 2013; Alnagar et al., 2018; Jones et al., 2019). It is needed to apply new teaching aids which are safer, more economical and more effective in visualizing the anatomical structure and its surrounding relations to improve the quality of anatomy learning.

P40 plastination technique and CT scanning confer highly qualified teaching aids for sectional anatomy (Latorre et al., 2002). The current study introduced two recent teaching carrels of the donkey brain including sheet plastination using P40 and its corresponding CT images to describe the brain anatomical structures for the benefits of radiologists, veterinary clinicians and also for accurate detection of small lesions by surgeons. CT images of the donkey cranium served as a reference for different anatomical structures of the brain and interpreted well with corresponding sagittal plastinated sections, except some structures could not be seen on the corresponding CT images. Lieve et al. (2005) identified numerous structures of the anatomic sections of canine brain using the CT images. CT imaging of the brain provided an amazing view and a good method in the diagnosis of the cranium disorders in the donkey. Lieve et al. (2005) used CT scanning for diagnosis of neuropathological conditions of the dog brains. The current study clarified the normal neuroanatomical structures to detect the pathological one. CT imaging in veterinary medicine is limited due to its expensive cost, less availability and the size of animals such as foals and adult horses (MacKay 2005; Dickey et al. 2011).

Most of the anatomic atlases for CT imaging obtained from comparing between in vivo images and the corresponding formalized anatomical slices obtained ex vivo (Solano and Brawer 2004: Probst et al 2005). The use of plastinated P40 slices accompanied with CT brain scanning allows to better understand complex anatomical structures and their adjacent tissues. Moreover, plastinated specimens facilitate the study of three-dimensional characteristics in certain structures such as deep nuclei, the origin of the cranial nerves and extension of the ventricular system. Legrand and Carlier (1999) identified the choroid plexus of the lateral ventricles by CT evaluation of the dog head.

Parallel with Cabreraa et al. (2015), the CT images of the brain and associated structures of normal neonatal foals provided excellent detail of clinical anatomy. Previous studies reported the normal anatomy of the equine head showed similar results with CT images (Arencibia et al., 2000; Smallwood et al., 2002; De Zani et al., 2010). Although, the findings of the present study and Karen et al. (2000) noticed that most of the cranial nerves (VII, IX, X, XI, and XII) surrounding the pouches could not be identified on CT images. In agreement with Assheuer and Sageer (1997), the presence of CSF in the ventricles and subarachnoid space facilitated the accurate identification of the surrounding structures and tissues in CT images obtained in the present investigation.

The present study found a precise correlation between sectional CT images and sheet P40 plastination. Some morphological parts observable in plastinated slices were more accurate and clearer than in CT images. Thus, studying of plastinated specimens improve the diagnosis, understanding of clinical signs and pathology of some central nervous system lesions (Reina et al., 2015). In present study revealed that both thin plastinated P40 slices and CT brain images were helpful in differentiating between white and gray matter. Morphological characteristics of the ventricular system, as well as the basal ganglia, were observed in P40 slices. In addition, plastinated slices conferred detailed knowledge about very small anatomical structures that cannot be distinguished on CT images, for example, some brainstem nuclei. The present study agreed with a study by Pauline et al. (2015) who reported the obtained brain P40 slices were clean, dry, odorless, light, non-toxic, non-fragile, not sticky to touch and durable, however, CT imaging showed better anatomical details of the organs than plastinated slices that were inconsistent with findings from the current study.

The P40 plastination sections of donkey brain have enough rigidity compared to formalized specimens, due to enough curing. Plastination sections were more economical and easier to use for teaching purposes. The weight of plastinated sheets with P40 is about one-tenth of the weight of formalized one (O'Sullivan and Mitchell, 1995 and Weiglein, 1997). Five steps followed during the plastination of P40 technique were in accordance with Sivrev et al. (2013). Although Sivrev et al. (2013) and Henry and Latorre (2007) had used $10 \%$ formalin solution (4-6 weeks) for fixation of the brain, this study added that, the well-fixed brains may need more time (1-2 weeks) in 5\% formalized solution. The slicing procedure followed in the present study was similar to that mentioned by Mircea-Constantin et al. (1999). The present study agreed with Henry and Latorre (2007) that flushing of the brain slices should be performed in cool running tap water for one or two days to complete removal of debris and formalin.

Although dehydration leads to shrinkage, the P40 technique is much better than the S10 standard one for plastination of brain slices. Shrinkage is the main problem in plastination processes, which in turn depends on the technique used (S10, E12 or P40). A notable shrinkage will decrease the value of the specimens due to change its shape and size (Sora et al., 2002). Mircea-Constantin et al. (2015) suggested that shrinkage rates under $10 \%$ is normal and indicate correct plastination procedure. In the present study shrinkage rate of $8 \%$ was observed. 
The time and concentrations of specimen dehydration in the present study were in agreement with Sivrev et al. (2013). The ratio of specimen weight to volume of acetone was 1:10 in accordance with Henry and Latorre (2007). Henry and Latorre (2007) and Sivrev et al. (2013) used polyester P40 with hardener A4 in ratio 100:2 whereas activator A9 was used in the present study.

In the study by Sivrev et al. (2013), curing of P40 resin was done by exposure to artificial UVA and sunlight. Although the mentioned study used 40 watts UVA light tubes in hardening while 200 watts light was used in the present study. Henry and Latorre (2007) stated that P40 resin must be kept in dark as UVA light works as the catalyst for polymerization. Arencibia et al. (2003) turned on the UV lights for 15 minutes then turned off for 30 minutes to avoid excess heat release during the curing step and used a ventilator to cool the chambers.

In the present study, using semi-transparent P40 slices from the imaged specimens of the same animal allowed accurate assessment of CT images in many anatomic structures. Though using brains of different animals in both techniques may provide asymmetric levels of P40 sections and CT images. Most features of the brain identified on anatomic sections could be identified on the corresponding CT scans despite the low contrast between anatomic structures and adjacent bony and soft tissues. The rapid diagnosis of diseases by using imaging techniques requires a deep detailed knowledge of normal anatomy, three-dimensional morphology and the topographical relationships with adjacent structures which were achieved by sheet $\mathrm{P} 40$ brain slices. Most the veterinary medical students have the same opinion that using P40 sheet plastination of the brain will greatly facilitate the understanding of the neuroanatomical structure especially in collaboration with labeled CT images.

\section{CONCLUSION}

P40 plastination technique was developed as a quick, less expensive and less complex method for preparing of brain slices which are suitable for teaching purposes. This technique provided translucent brain slices which is a new innovative method in sectional anatomy. These unique slices are excellent teaching aids especially when are correlated parallel with modern diagnostic images such as CT. Both techniques allow an accurate assessment of many complex anatomical three-dimensional structures and relationships which has wide application in neurology, neurosurgery, radiology, and neuroradiology. In addition, the interpretation of CT images is easier in the presence of the corresponding plastinated brain sections.

\section{DECLARATIONS}

\section{Acknowledgments}

The authors extend their appreciation to Prof. Dr. Aly El Din Abd El Basset Aly, Prof. Dr. Atef Abd El Aziz El Said and to all staff members of Anatomy and Embryology Department, Faculty of Veterinary Medicine, Zagazig University, Egypt for their kind support during the study.

\section{Competing interests}

The authors declare that they have no competing interests.

\section{Consent to publish}

All authors gave their informed consent prior to their inclusion in the study.

\section{Authors' contributions}

Dr. Sherif Khayri Abdelmoati Mohamed collected the samples, designed the P40 experiment and sent animal for CT imaging, also was responsible for writing, revising and submission of the manuscript. Dr. Eman Ismail El-behery and Dr. Eman Abdelrahman Ahmed Mahdy obtained the data, critically revised the manuscript for important intellectual contents. All authors approved the final version of manuscript before publication.

\section{REFERENCES}

Alnagar Fahima, Shmela ME, Alrtib A, Abdalmula A (2018). Health adverse effects of formaldehyde exposure to students and staff in gross anatomy. International Journal of Scientific Research and Management, 6(2):93. DOI:http://doi.org/ 10.18535/ijsrm/v6i2.mp02

Arencibia A, Gil F, Rivero M, Ramirez G, Vaquezauton JM and Henry RW (2003). P40 and S10 plastinated slices: An aid to interpreting MR images of the equine tarsus. Journal of the International Society for Plastination, 18:14-22.

Arencibia A, Vazquez JM, Rivero M, Latorre R, Sandoval JA, Vilar JM and Ramírez JA (2000). Computed tomography of normal cranioencephalic structures in two horses. Anatomia, Histologia, Embryologia, 29:295-299. DOI: https://doi.org/10.1046/j.1439-0264.2000.00278.x

Assheuer J and Sageer M (1997). Head MRI and CT atlas of the dog. Blackwell Science, Berlin, pp. 1-81.

Cabreraa L, Arencibia A, Rizkallal C, Blanco D, Farray D, Díaz-Bertrana ML, Carrascosa C and Jaber JR (2015). Computed tomographic imaging of the brain of normal neonatal foals. Archivos de medicina veterinaria, 47: 209-214. DOI: http://dx.doi.org/10.4067/S0301-732X2015000200012 
De Zani D, Borgonovo S, Biggi M, Vignati S, Scandella M, Lazzaretti S, Modina S and Zani D (2010). Topographic comparative study of paranasal sinuses in adult horses by computed tomography, sinuscopy and sectional anatomy. Veterinary Research Communications, 34: 13-16. DOI: http://10.1007/s11259-010-9381-6

Dickey EJ, Long SN and Hunt RW (2011). Hypoxic ischemic encephalopathy, What we can learn from humans? Journal of Veterinary Internal Medicine, 25: 1231-1240. DOI: http://10.1111/j.1939-1676.2011.00818.x

Henry RW and Latorre R (2007). Polyester Plastination of Biological Tissue: P40 Technique for Brain Slices. Journal of the International Society for Plastination, 22: 59-68.

Jonathon DR, Thomas HW, Justin DP and Renate W (2016). Standing Equine Computed Tomography: technique and clinical use. EAVDI yearbook. Sponsored by European Association Of Veterinary Diagnostic Imaging, ltd. Prepared for publishing by Mike French. High Street Sawston Cambridge, United Kingdom.

Jones W, Greytak S, Odeh H, Guan P, Powers J, Bavarva J and Moore, H M (2019). Deleterious effects of formalin fixation and delays to fixation on RNA and miRNA-Seq profiles. Scientific Reports, 9:6980. DOI: https://doi.org/10.1038/s41598-01943282-8

Karen LM, Richard DP, Thomas LS, Stashak TS and Billie Arceneaux RT (2000). Computed tomographic imaging of the equine head. Veterinary Radiology \& Ultrasound, 41(6):491-497. DOI: https://doi.org/10.1111/j.1740-8261.2000.tb01876.x

Latorre R, Vaquez JM, Gil F, Ramirez G, Lopez-Albors O, Ayala M and Arencibia A (2002). Anatomy of the equine tarsus: A study by MRI and macroscopic plastinated sections (S10 and P40). Journal of the International Society for Plastination, 17: 26.

Legrand J and Carlier B (1999). CT examination of the brain of the dog I. Conduct of the examination and anatomical landmarks. Journal of Veterinary Medicine, 137: 193-196. Doi: https://doi.org/10.1016/S1257-5143(09)50843-6

Lieve MD, Ingrid MG, Sofie AV, Paul JS and Henri J (2005). Computed tomography and cross-sectional anatomy of the brain in clinically normal dogs. American Journal of Veterinary Research, 66 (10): 1743-1757. PMID: 16273906.

MacKay RJ (2005). Neurological disorders of neonatal foals. Veterinary Clinics of North America: Equine Practice, 21: $387-406$. DOI: https://doi.org/ 10.1016/j.cveq.2005.04.006

Mircea-Constantin S, Peter B and Hannes T (1999). P40 Plastination of human brain slices: comparison between different immersion and impregnation conditions. Journal of the International Society for Plastination, 14 (1): 22-24.

Mircea-Constantin S, Maximillian B, Petru M, Horia P and Ioan S (2015). Slice plastination and shrinkage. Materiale Plastice, 52 (2): 186-189. Available at: http://www.revmaterialeplastice.ro.

Morrow KL, Park RD, Spurgeon TL, Stashak TS and Arceneaux B (2000). Computed tomographic imaging of the equine head. Veterinary Radiology \& Ultrasound, 41: 491-497. DOI: https://doi.org/10.1111/j.1740-8261.2000.tb01876.x

Nomina Anatomica Veterinaria (2017). 6th ed, prepared by the International Committee on Veterinary Gross Anatomical Nomenclature (I.C.V.G.A.N.) and authorized by the General assembly of the World Association of Veterinary Anatomists (W.A.V.A.), Knoxville,T.N (USA). Published by the Editorial Committee, Hannover, Columbia, Ghent, and Sapporo. 119-135.

Nora SM, Tex S and Taylor (2002). Anesthesia of donkeys and mules: how they differ from horses. International Veterinary Information Service (in depth: mule/donkey medicine and surgery), 48: 110-112.

O'Sullivan E and Mitchell BS (1995). Plastination for gross anatomy teaching using low cost equipment. Surgical and Radiologic Anatomy, 17(3): 277-81. PMID: 7502194

Pauline S, Rabi RS, Sridhar G and Suganthy R (2015). Comparison of CT numbers of organs before and after plastination using standard S-10 technique. Clinical Anatomy, 28: 431-435. DOI: https://doi.org/10.1002/ca.22514

Probst A, Henninger W and Willmann M (2005). Communications of normal nasal and paranasal cavities in computed tomography of horses. Veterinary Radiology and Ultrasound, 46, 44-48. DOI: https://doi.org/10.1111/j.1740-8261.2005.00008.x

Reda M and Roger J (2018). Production and use of plastinated anatomical specimens as teaching and learning tools in veterinary gross anatomy in the Caribbean. Journal of Advanced Veterinary and Animal Research, 5 (1): 44-52. DOI: http://doi.org/10.5455/javar.2018.e245

Reina de la Torre F, Carrera-Burgaya A, Bataller-Jordà F, Pedraza S, Puig-Camps A, San-Molina J and Girona ES (2015). Correlation between thin sheet plastinated slices and CT and MRI images of the central nervous system. European Society of Radiology, Poster No.: C-2490:1-16. DOI: https://doi.org/10.1594/ecr2015/C-2490

Renukaradhya1 GJ, Shilpa VS and Roopa SR (2018). Plastination: through ages. Journal of Advanced Clinical \& Research Insights, 1: 72-74. DOI: https://doi.org/10.15713/ins.jcri.215

Sivrev DP, Hamza SR, Dimitrov ND and Georgieva AI (2013). Using of P40 technique for brain sheet plastination. Faculty of Medicine, University of Thrace, St. Zagora, Bulgaria. UDC 57-611.

Smallwood JE, Wood BC, Taylor E and Tate Jr LP (2002). Anatomic reference for computed tomography of the head of the foal. Veterinary Radiology \& Ultrasound, 43: 99-117. DOI: https://doi.org/10.1111/j.1740-8261.2002.tb01657.x

Solano M and Brawer RS (2004). CT of the equine head: technical considerations, anatomical guide and selected diseases. Clinical Techniques in Equine Practice, 3: 374-388. DOI: https://doi.org/10.1053/j.ctep.2005.02.016

Sora MC, Strobl B, Staykov D and Traxler H (2002). Optic nerve compression analyzed by using plastination. Surgical and Radiologic Anatomy, 24(4): 205-208. DOI: https://doi.org/ 10.1007/s00276-002-0037-2

Von Hagens G (1994). Plastination of brain slices according to the P40 procedure. A step-by-step description. Heidelberg, 1994, 23 p. 23 pages.

Von Hagens G, Tiedemann K and Kriz W (1987). The current potential of plastination. Anatomy and Embryology, 175(4):411-421.

Weiglein AH (1997). Plastination in the Neurosciences. Acata Anatomica, 158(1): 6-9. DOI: https://doi.org/10.1159/000147902 